\title{
Assessment of the apically extruded debris between a rotary system, a reciprocating system and hand files during the root canal instrumentation of the deciduous molars
}

\section{Ocena przepchnięcia wierzchołkowego zawartości kanałów po zastosowaniu systemu rotacyjnego, recyprokalnego i pilników ręcznych podczas opracowywania kanałów korzeniowych mlecznych zębów trzonowych}

\author{
Ibrahim Alnassar ${ }^{1, A-D, F}$, Ahmad Saleem Alsafadi2 ${ }^{2},-F$, Chaza Kouchajil',A,C,E,F \\ ${ }^{1}$ Department of Pediatric Dentistry, Faculty of Dentistry, Damascus University, Syria \\ ${ }^{2}$ Department of Orthodontics, Faculty of Dentistry, Damascus University, Syria \\ A - research concept and design; $\mathrm{B}$ - collection and/or assembly of data; $\mathrm{C}$ - data analysis and interpretation; \\ $D$ - writing the article; $E$ - critical revision of the article; $F$ - final approval of the article
}

\begin{abstract}
Address for correspondence
Ibrahim Alnassar

E-mail: ibrahimalnassar1991@gmail.com
\end{abstract}

Funding sources

None declared

Conflict of interest

None declared

Received on August 25, 2018

Reviewed on 0ctober 10, 2018

Accepted on November 8, 2018

Published online on March 29, 2019

Cite as

Alnassar I, Alsafadi AS, Kouchaji C. Assessment of the apically extruded debris between a rotary system, a reciprocating system and hand files during root canal instrumentation of the deciduous molars. Dent Med Probl. 2019;56(1):53-57. doi:10.17219/dmp/99655

DOI

10.17219/dmp/99655

Copyright

๑ 2019 by Wroclaw Medical University

This is an article distributed under the terms of the

Creative Commons Attribution Non-Commercial License

(http://creativecommons.org/licenses/by-nc-nd/4.0/)

\begin{abstract}
Background. One of the factors that most negatively affect the endodontic instrumentation process in primary teeth is the presence of extruded debris in the periapical region. Therefore, different techniques have been evaluated to reach an answer to the question regarding which root canal preparation method produces the least amount of debris extrusion.

Objectives. The main objective of this study was to assess the amount of debris extrusion as well as irrigation associated with 3 different instrumentation techniques: a rotary system (PROTAPER NEXT ${ }^{\circledR}$ - PTN), a reciprocating system (WaveOne ${ }^{\circledR}-$ W0) and hand K-files.
\end{abstract}

Material and methods. Forty-eight primary mandibular molars with a single distal canal were selected and randomly divided into 3 groups $(n=16)$. Three different techniques were used for the canal instrumentation of each group, comprising PTN, WO and hand K-files. Pre-weighed Eppendorf tubes were used for the collection of debris extrusion, then stored in an incubator at $70^{\circ} \mathrm{C}$ for 5 days. A one-way analysis of variance (ANOVA) test was used for data analysis, followed by Tukey's post hoc test.

Results. Statistically significant differences were found while comparing the PTN and WO systems with the hand files. Both PTN and WO showed less debris extrusion toward the periapical tissues than the hand files. Still, no statistically significant differences were seen between the PTN and WO groups.

Conclusions. Generally, debris extrusion occurred in all of the 3 experimental groups. The PTN and W0 systems showed the least debris extrusion as compared to the hand files during the root canal instrumentation of the primary teeth, and for these reasons along with the shorter operating time, it may be concluded that using rotary and reciprocating systems rather than manual files is highly advisable. However, a clinical assessment is suggested.

Key words: extruded debris, hand files, rotary system, primary teeth, reciprocating system

Słowa kluczowe: przepchnięta zawartość kanałów, pilniki ręczne, system rotacyjny, zęby mleczne, system recyprokalny 


\section{Introduction}

Keeping the primary dentition healthy is crucial for maintaining normal development of the jawbones, natural muscle function, good speech, and even natural eruption of the secondary dentition. However, it has been reported that premature eruption of the primary teeth may lead to many problems, some of which are bad oral habits and changes in the arch dimensions, as well as disturbances in the eruption sequence of the permanent dentition. ${ }^{1}$

Despite the fact that the endodontic treatment of the primary teeth with the optimal preparation has been recommended as a successful therapy for irreversible pulpitis or even pulp necrosis, ${ }^{2}$ a few reports have mentioned that using traditional endodontic files for this purpose is time-consuming and causes fatigue for both dentists and patients. ${ }^{3}$

Since the introduction of rotary-file systems for the endodontic treatment of the primary teeth by Barr and his colleagues in 2000, ${ }^{4}$ many studies have reported the efficacy of these instruments in maintaining the original root canal anatomy of the primary teeth and reducing the frequent errors that usually occur during the traditional treatment process with the use of normal hand files. ${ }^{4,5}$ The use of nickel-titanium (NiTi) rotary instruments makes the endodontic treatment faster and easier with less file breakage incidents. Furthermore, NiTi instruments provide better shaping for the cleaning procedure, irrigation and obturation during the root canal therapy. ${ }^{5}$

Debris extrusion resulting from the endodontic preparation and irrigation during the root canal treatment, including dentinal fragments, microorganisms and irrigation solutions, can all cause pain and inflammation, and delay the healing of the periapical tissues. Most traditional techniques, which depend on normal hand files, lead to these undesired effects. Therefore, eliminating debris extrusion in the apical region has been recommended for the successful root canal therapy of the primary teeth. ${ }^{6}$

The primary teeth are subject to physiologic resorption due to the eruption of the succedaneous teeth. This causes more apical foramen enlargement of the primary teeth, which, in turn, allows more extrusion of the debris periapically. ${ }^{7}$ However, the amount of the extruded debris is affected by the techniques and systems used during the endodontic treatment..$^{8-10}$

Recently, PROTAPER NEXT ${ }^{\circledR}$ (PTN) rotary files (Dentsply Maillefer, Ballaigues, Switzerland) have utilized different designs that contribute to both increased flexibility and increased cyclic fatigue resistance. These designs incorporate an M-wire alloy, which, in turn, enables an off-centered rectangular cross-section and the application of variable tapers of rotary files. ${ }^{11}$
Reciprocating rotation was suggested as an alternative to continuous rotation for the preparation of curved canals by applying a single instrument. ${ }^{12}$ This technique forms the root canal safely, ${ }^{13}$ enabling better irrigation as well as removing less dentin from the internal walls of the canals, especially in the danger zones, which decreases the possibility of damage or fracture in the dentinal walls or in the file itself. ${ }^{14}$ The WaveOne ${ }^{\circledR}$ (WO) system (Dentslpy Maillefer) applies a reciprocating movement using just 1 instrument with 3 size options (small - 21/06; primary - 25/08; and large - 40/08). ${ }^{15}$

The aim of this study was to evaluate the differences in the amount of the extruded debris between the WO file, PTN files and hand K-files, used in the treatment of the primary teeth.

\section{Material and methods}

The protocol of this in vitro study was approved by the research ethics committee of Damascus University, Syria (No. of the ethical approval: 1788/2017). This study was carried out on 48 distal canals of primary mandibular molars extracted due to periapical pathology and preventive orthodontic treatment. The teeth were cleaned of the external debris and soft tissue remnants, then stored in a saline solution at room temperature to be used later.

The study, according to the required criteria, involved primary mandibular molars with $2 / 3$ of the root present and the moderate curvature of the distal root ranging between $10^{\circ}$ and $20^{\circ}$, according to the Schneider protocol, ${ }^{16}$ without pathological resorption, fracture, cracks, or caries in the root. The teeth were examined by means of digital periapical radiography to confirm the presence of a single canal.

Each primary tooth was sectioned at the furcation area using a low-speed diamond saw (IsoMet ${ }^{\mathrm{TM}}$ 1000; Buehler, Lake Bluff, USA) with water cooling to separate the mesial root with its respective section of the crown from the distal one. Then, the mesial portion was discarded and the distal portion was kept for further investigations. The access cavities were prepared using an Endo- $Z^{\circledR}$ bur (Dentsply Maillefer) at a high speed under cooling. All root canals were prepared by the same researcher and randomly divided into 3 groups.

A size $10 \mathrm{~K}$-file (Dentsply Maillefer) was inserted in the distal root canal to verify its patency. This was followed by determining the working length; firstly, the size $10 \mathrm{~K}$-file was inserted into the distal canal until it became visible at the apical foramen, then the working length was calculated by subtracting $1 \mathrm{~mm}$ from the previous measurement. Moreover, a radiograph was taken using the parallel technique to ensure correct measurement of the working length. It was considered that the canals with dimensions greater than those of the International Organization for Standardization (ISO) size 15 were to be excluded. ${ }^{17}$ 
In this study, the experimental model mentioned by Myers and Montgomery was used for the evaluation of the extruded debris collection (Fig.1). ${ }^{18}$ A hole was created in each stopper of the Eppendorf tube and each tooth was inserted under pressure through the stopper to the level of the cementoenamel junction. In order to ensure balance of the air pressure between the inside and outside of the tube, a 27-gauge needle was inserted into each Eppendorf tube. Then, each stopper with its tooth and needle were attached to the Eppendorf tube, which, in turn, was fitted into a vial. All the equipment was handled using the vial without touching it with fingers. Furthermore, a microbalance was used to weigh the Eppendorf tube with $10^{-5}$ precision. Three weights were taken sequentially, and the mean value was registered for each tube. The irrigation protocol was standardized using $5 \mathrm{~mL}$ of distilled water with a 29-gauge needle (NaviTip ${ }^{\circledR}$; Ultradent Products, Inc., South Jordan, USA) after using each file or after 3 pecks of the reciprocating file (as recommended by the manufacturer). The 48 specimens were randomly assigned to 3 groups after marking each tooth for encoding. Each group was made up of 16 samples as follows:

- hand file control group (group 1): hand preparation was completed using a stainless steel K-file taper 0.02 in the step-back technique, starting with size 15 and continuing in the following sequence: 20, 25 and 30;

- PTN (group 2): the PTN files were applied using an endodontic motor (X-Smart Plus; Dentsply Maillefer) in the following order: X1 (size 17, taper 0.04) and X2 (size 25, taper 0.06); the rotational speed was set at $300 \mathrm{rpm}$ and $2 \mathrm{Ncm}$ torque (according to the manufacturer's instructions); brushing movements were performed gently using an in-and-out motion;

- WO group (group 3): a small file (21/06) was used with a reciprocal motion (according to the manufacturer's instructions).

The evaluation of the debris was performed by a single, blinded operator. Finally, the Eppendorf tubes were separated from the vials after the successful completion of the canal preparation. Then, the debris stuck to the root surface was collected by rinsing the root with $1 \mathrm{~mL}$ distilled water in the Eppendorf tube. Evaporation of the distilled water was performed using an incubator at $70^{\circ} \mathrm{C}$
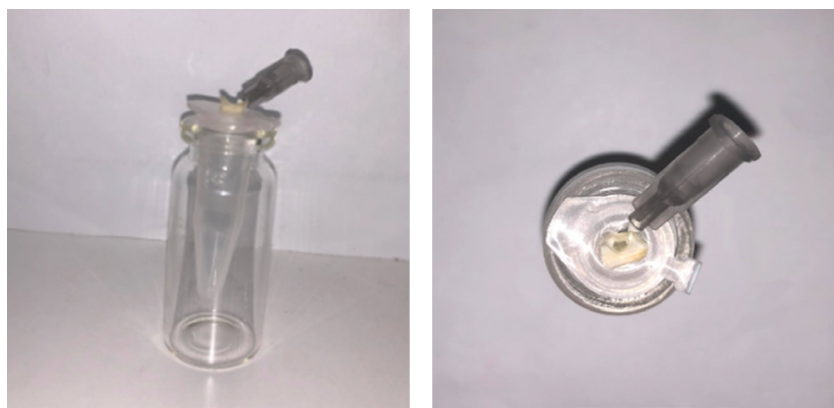

Fig. 1. Experimental system used to evaluate the debris extrusion for 5 days before weighing the dry debris. ${ }^{19}$ The net weight of the dry debris was calculated by subtracting the weight of the empty Eppendorf tube from the total weight.

\section{Statistical analysis}

The Kolmogorov-Smirnov test showed that the data was normally distributed. Then, Levene's test for homogeneity was used to confirm the homogeneity between the variances. The differences between the groups were analyzed with one-way analysis of variance (ANOVA), followed by Tukey's post hoc test for multiple comparisons, and the level of significance was set at 0.05. The IBM SPSS software v. 20.0 (IBM SPSS, Inc., Chicago, USA) was used for data analysis.

\section{Results}

The mean values, standard deviations $(S D)$ and ANOVA results regarding the 3 groups are listed in Table 1 . The $p$-value was $\leq 0.05$ for the ANOVA test, which showed significant differences between the experimental groups. Tukey's post hoc test showed that there were no statistically significant differences in the extruded debris between the PTN and WO groups $(p>0.05)$, as shown in Table 2 . The highest amount of the apically extruded debris was seen in the hand file group. In other words, there were statistically significant differences between the PTN and manual file group, in addition to the presence of statistically significant differences between the WO and manual file groups, but at the same time there were no statistically significant differences between the PTN and WO groups while comparing their results.

Table 1. Weight of the extruded debris in the experimental groups (one-way analysis of variance - ANOVA)

\begin{tabular}{|l|c|c|c|c|c|}
\hline \multicolumn{1}{|c|}{ Group } & $\mathrm{n}$ & Mean & SD & $\mathrm{F}$ & $p$-value \\
\hline WO & 16 & 0.00242 & 0.00033 & & \\
PTN & 16 & 0.00262 & 0.00030 & 72.716 & $0.000^{*}$ \\
Hand file & 16 & 0.00379 & 0.00039 & & \\
\hline
\end{tabular}

WO - WaveOne; PTN - PROTAPER NEXT; SD - standard deviation;

* significant difference at $p \leq 0.05$.

Table 2. Pairwise comparisons with Tukey's test

\begin{tabular}{|lc|c|c|}
\multicolumn{2}{c|}{ Pair } & $\begin{array}{c}\text { Mean differences } \\
\text { of debris weight }\end{array}$ & $p$-value \\
WO & PTN & -0.00019 & 0.240 \\
WO & Hand files & -0.00137 & $0.000^{*}$ \\
PTNt & Hand files & -0.00117 & $0.028^{*}$ \\
\hline
\end{tabular}

*significant difference at $\mathrm{p} \leq 0.05$. 


\section{Discussion}

Root canal treatment may lead to dramatic effects in the periapical tissues. Many inflammatory changes and pain that occur during the mechanical and chemical preparation of the root canals are a result of debris extrusion into the periapical region. The debris contains dentinal particles, irrigation solutions, necrotic pulp, and microorganisms. On the other hand, the undesirable effects of the extruded debris pose a threat to the permanent dentition, as they may alter the morphology of the permanent tooth germ. ${ }^{6}$ Therefore, the major purpose of this study was the assessment of the apically extruded debris and irrigants as a result of the root canal preparation with different instrumentation system techniques.

In the present study, $5 \mathrm{~mL}$ of distilled water was used for the root canal irrigation to prevent the crystallization of sodium hypochlorite, which may cause misleading findings of the debris. ${ }^{17}$ The generally accepted method of Myers and Montgomery was used for the collection of the extruded debris. ${ }^{18}$ There have been different results obtained in studies in vivo and in vitro due to the fact that the normal periapical tissues act as a physical barrier that helps to control the extrusion of the necrotic debris. ${ }^{20}$ Therefore, there is a limitation when applying the results of this study clinically due to the lack of a back pressure, naturally caused by the periapical tissues. Floral foam has been mentioned in the literature as a substance used for the periapical tissue stimulation. ${ }^{21}$ However, this material may absorb the irrigating solution as well as the resulting debris, and hence influence the results.

The distal root of the primary mandibular molar was chosen for this study, because it has a large single canal, a regular canal outline and less intracanal divergence as compared to the mesial root of the primary mandibular molar. The current study revealed that all of the preparation techniques caused the apical extrusion of debris and irrigants. It is in agreement with the findings of other studies, which have mentioned the lack of any existing technique that could totally prevent debris extrusion. ${ }^{22,23}$ Different authors have stated that the PTN system extruded significantly less debris than the hand file technique. ${ }^{23,24}$ Madalena et al. reported that the amount of the apically extruded debris was smaller in the case of the root canal preparation with a single reciprocating file (WO) as compared to the hand files. ${ }^{25}$ This study confirmed that observation.

To the best of our knowledge, no study has ever evaluated the apical extrusion of the debris during the root canal instrumentation of the primary teeth by comparing the PTN and WO systems. Thus, the results of our study can only be compared with the results of other studies that have used both instrumentation techniques in the treatment of the permanent teeth. In this study, no statistically significant differences between the reciprocating single-file WO system and the rotary multiple-file PTN system were observed, which corresponds to the observations of Ozsu et al. ${ }^{26}$
There are several factors responsible for differences between the root canal preparation systems, such as technique, direction and kinematics of the instrumentation. Different files have different cross-sectional designs. For example, the PTN file has a rectangular cross-section with a unique design (an offset center of mass and rotation). This design provides greater cross-sectional space for reinforced cutting, loading and the movement of the debris toward the orifice area of the canal, and results in less extruded debris in the PTN group when compared with the hand file group. ${ }^{27}$ Another reason for decreasing the amount of debris in the PTN group could be the instrumentation technique. Since the PTN file is a rotary system file, the method used for the canal preparation is the crown-down technique, depending on the early flaring of the coronal area of the canal, which may increase directing the debris toward the orifice area during the rotational movement. ${ }^{28}$ On the other hand, the middle and coronal portions of the WO files have a convex triangular cross-section, whereas the tip portion has a modified convex triangular cross-section. ${ }^{13}$ There is consensus that balanced forces lead to good control of the apically extruded debris. Due to the reciprocating motion of the WO file, leading to automatically balanced forces with less pressure, the amount of the apical debris during the canal preparation is well-controlled. ${ }^{29}$

Finally, regarding the hand file group, the step-back technique was used for the root canal shaping of the primary teeth during biomechanical preparation. The hand file was acting as a piston in the apical area of the canal, which increased the amount of the apically extruded debris in the periapical region. ${ }^{30}$

\section{Conclusions}

The results of the present study showed that all instrumentation techniques used for the root canal preparation of the primary teeth caused debris extrusion. However, the hand files extruded more debris than both PTN and WO, whereas the PTN and WO systems both extruded less debris and showed better results.

\section{ORCID iDs}

Ibrahim Alnassar (1) https://orcid.org/0000-0002-8197-9171

Ahmad Saleem Alsafadi (D) https://orcid.org/0000-0002-6313-2014

Chaza Kouchaji (D) https://orcid.org/0000-0002-1403-7037

\section{References}

1. Kucukyilmaz E, Savas S, Saygili G, Uysal B. Evaluation of apically extruded debris and irrigant produced by different nickel-titanium instrument systems in primary teeth. J Contemp Dent Pract. 2015;16(11):864-868.

2. Fuks $A B$, Eidelman E. Pulp therapy in the primary dentition. Curr Opin Dent. 1991;1(5):556-563.

3. Silva LA, Leonardo MR, Nelson-Filho P, Tanomaru JM. Comparison of rotary and manual instrumentation techniques on cleaning capacity and instrumentation time in deciduous molars. J Dent Child (Chic). 2004;71(1):45-47 
4. Barr ES, Kleier DJ, Barr NV. Use of nickel-titanium rotary files for root canal preparation in primary teeth. Pediatr Dent. 2000;22(1):77-78.

5. Nagaratna PJ, Shashikiran ND, Subbareddy VV. In vitro comparison of NiTi rotary instruments and stainless steel hand instruments in root canal preparations of primary and permanent molar. J Indian Soc Pedod Prev Dent. 2006;24(4):186-191.

6. Adl A, Sahebi S, Moazami F, Niknam M. Comparison of apical debris extrusion using a conventional and two rotary techniques. Iran Endod J. 2009;4(4):135-138.

7. Onçağ Ö, Hoşgör M, Hilmioğlu S, Zekioğlu O, Eronat C, Burhanoğlu D. Comparison of antibacterial and toxic effects of various root canal irrigants. Int Endod J. 2003;36(6):423-432.

8. Koçak S, Koçak MM, Sağlam BC, Türker SA, Sağsen B, Er Ö. Apical extrusion of debris using self-adjusting file, reciprocating single-file, and 2 rotary instrumentation systems. J Endod. 2013;39(10):1278-1280.

9. Pinheiro SL, Araujo G, Bincelli I, Cunha R, Bueno C. Evaluation of cleaning capacity and instrumentation time of manual, hybrid and rotary instrumentation techniques in primary molars. Int Endod J. 2012;45(4):379-385.

10. Berutti E, Chiandussi G, Paolino DS, et al. Effect of canal length and curvature on working length alteration with WaveOne reciprocating files. J Endod. 2011;37(12):1687-1690.

11. Elnaghy AM, Elsaka SE. Evaluation of root canal transportation, centering ratio, and remaining dentin thickness associated with ProTaper Next instruments with and without glide path. J Endod. 2014;40(12):2053-2056

12. Kim HC, Kwak SW, Cheung GS, Ko DH, Chung SM, Lee W. Cyclic fatigue and torsional resistance of two new nickel-titanium instruments used in reciprocation motion: Reciproc versus WaveOne. J Endod. 2012;38(4):541-544.

13. Berutti E, Chiandussi G, Paolino DS, et al. Canal shaping with WaveOne Primary reciprocating files and ProTaper system: A comparative study. J Endod. 2012;38(4):505-509.

14. Metzger Z, Teperovich E, Zary R, Cohen R, Hof R. The self-adjusting file (SAF). Part 1: Respecting the root canal anatomy - a new concept of endodontic files and its implementation. J Endod. 2010;36(4):679-690.

15. Plotino G, Grande NM, Testarelli L, Gambarini G. Cyclic fatigue of Reciproc and WaveOne reciprocating instruments. Int Endod J. 2012;45(7):614-618.

16. Schneider SW. A comparison of canal preparations in straight and curved root canals. Oral Surg Oral Med Oral Pathol. 1971;32(2):271-275.

17. Huang X, Ling J, Wei X, Gu L. Quantitative evaluation of debris extruded apically by using ProTaper Universal Tulsa rotary system in endodontic retreatment. J Endod. 2007;33(9):1102-1105.

18. Myers GL, Montgomery S. A comparison of weights of debris extruded apically by conventional filing and Canal Master techniques. J Endod. 1991;17(6):275-279.

19. Bürklein S, Schäfer E. Apically extruded debris with reciprocating single-file and full-sequence rotary instrumentation systems. J Endod. 2012;38(6):850-852.

20. De-Deus GA, Silva EJNL, Moreira EJ, Neves AA, Belladonna FG, Tameirão M. Assessment of apically extruded debris produced by the self-adjusting file system. J Endod. 2014;40(4):526-529.

21. Hachmeister DR, Schindler WG, Walker WA III, Thomas DD. The sealing ability and retention characteristics of mineral trioxide aggregate in a model of apexification. J Endod. 2002;28(5):386-390.

22. Nayak G, Singh I, Shetty S, Dahiya S. Evaluation of apical extrusion of debris and irrigant using two new reciprocating and one continuous rotation single file systems. J Dent (Tehran). 2014;11(3):302-309.

23. Kirchhoff $A L$, Fariniuk LF, Mello I. Apical extrusion of debris in flatoval root canals after using different instrumentation systems. J Endod. 2015;41(2):237-241.

24. Thakur B, Pawar AM, Kfir A, Neelakantan P. Extrusion of debris from primary molar root canals following instrumentation with traditional and new file systems. J Contemp Dent Pract. 2017;18(11):1040-1044

25. Madalena IR, Carneiro SV, Osório SdRG, et al. Assessment of extruded debris in primary molars comparing manual and reciprocating instrumentation. Pesq Bras Odontoped Clin Integr. 2017;17(1):e3767.

26. Ozsu D, Karatas E, Arslan H, Topcu MC. Quantitative evaluation of apically extruded debris during root canal instrumentation with ProTaper Universal, ProTaper Next, WaveOne, and self-adjusting file systems. Eur J Dent. 2014;8(4):504-508.
27. Ruddle CJ, Machtou P, West JD. The shaping movement: Fifth generation technology. Dent Today. 2013;32(4):94,96-99.

28. Beeson TJ, Hartwell GR, Thornton JD, Gunsolley JC. Comparison of debris extruded apically in straight canals: Conventional filing versus profile .04 Taper series 29. J Endod. 1998;24(1):18-22.

29. McKendry DJ. Comparison of balanced forces, endosonic, and stepback filing instrumentation techniques: Quantification of extruded apical debris. J Endod. 1990;16(1):24-27.

30. Yeter KY, Evcil MS, Ayranci LB, Ersoy I. Weight of apically extruded debris following use of two canal instrumentation techniques and two designs of irrigation needles. Int Endod J. 2013;46(9):795-799. 
